\title{
Could Gamification Present a Significant Topic for the Philosophy of Sport?
}

\author{
Emanuel Hurych \\ Masaryk University, Faculty of Sports Studies, Brno
}

\begin{abstract}
This article focuses on the phenomenon of gamification in the context of the philosophy of sport. Gamification is usually understood as a process of adding games or game-like elements to some activity in order to encourage participation. It takes the techniques that game designers use to engage players and applies them to motivate people in different spheres of our lives.

It should be emphasized that gamification itself is not about games; it is not about the digital world, nor is it primarily about sport. However, it is a phenomenon that originated in the world of games and gained its content in the digital world. Gamification is also close to the phenomenon of play because it was invented by those people who were playing games.

The main question asked in the text is whether gamification, although it is not primarily about games or sports, can be a crucial topic for the philosophy of sport.

This article proposes some opportunities for philosophical approaches to gamification within kinanthropology. The ethical discourse is mentioned in the context of normative ethics. The ontological discourse is followed in the context of the digital world and the phenomenon of sportification.

One of the possible areas of interest in the philosophy of sport can be presented by monitoring and scheduling endurance sports activities. This issue is developed within the article on the ontological level, especially. The sociologically based study about gamification-form-above and gamification-from-below by Woodcock and Johnson is examined via Patočka's concept of three movements of human existence. It was included in the article mainly as an example to illustrate the great diversity of possible philosophical approaches.

It appears that gamification in sport is rapidly spreading, and it will be examined within different empirical studies more and more. This article argues that this phenomenon is also an interesting topic for the philosophy of sport.
\end{abstract}

Keywords: gamification, play, game, sport, philosophy.

\section{GAMIFICATION AS A PROCESS}

Gamification is usually understood as a process of adding games or game-like elements to some activity to encourage participation. Gamification takes the techniques that game designers use to engage players and applies them to motivate people in different spheres of our lives (Çeker \& Özdaml, 2017). Kim, Park and Baek $(2009,801)$ tried to identify the differences between gamification and game-based learning. They indicated that in game-based learning, learners arrive at their educational targets by playing games, which in short means learning via playing games. However, gamification has emerged entirely from the context of playing games. With gamification, games cannot therefore replace the learning process itself. Rather, it helps make learning a more participating activity and targets rather the overcoming of difficulties in learning over time (Codish and Ravid, 2014).

With the rapid development of cyber games and their penetrating the everyday lives of many young people, gamification becomes an essential issue for different study fields. Economic discourse is often used as a business strategy (Hamari et al., 2015). For pedagogy, it can present 
an educational method or teaching instrument (Ranchhod et al., 2014). Psychologists examine gamification as a method of motivation (Sailer et al., 2017).

In the context of sports, gamification provides a possibility for various empirical sociological studies. Koivisto and Hamari (2019a) conducted a systematic literature review of comparitive studies related to physical activity gamification. Accordingly, it seems applicable for developing some of our ideas expressed in a few following paragraphs.

A strong current of publications devoted to gamification in the context of kinanthropology is related to health issues and healthy movement activities. Here can be mentioned some articles published in the field of sports medicine, health, and treatment (Gabele et al., 2019; Allam et al., 2015). The context of lifestyle elements and a sedentary life also presents quite a frequent topic for some authors (e. g. Broom and Flint, 2018; Gremaud et al., 2018; Martínez-Gonzales, 1999).

Gamification can be applied as an ambivalent instrument in the field of physical activity. It can sometimes be perceived as something which encourages a sedentary lifestyle (Peng, Lin, and Crouse, 2011). On the other hand, some location-based games (such as Pokémon Go) and exergames can support healthy kinds of active human movement.

Koivisto and Hamari (2019a, 106) also argue: "Beyond physical activity becoming a way to play games, intentional gamification further attempts to adopt the motivational facets of gaming and implementing them into pursuits with direct health outcomes in mind."

Here we can mention an essential link between studies devoted to the phenomenon of a "healthy lifestyle" and searching for instruments that can support improvements in this field. This focuses on monitoring physical activities via applications in some electronic devices (mobile phones, smartwatches, fitness trackers, etc.).

The gameful interventions for increasing physical activity are primarily applied in the same way as gamification in general (Koivisto and Hamari, 2019b). They present point-based mechanics and activity goals and performance rankings, or visualizations of one's performance. Some innovative affordances include real-world activity, e. g., "steps, being transformed into a game currency in a virtual world," or "duel competitions between individuals for engaging individuals in physical activity" (Koivisto and Hamari, 2019a, 109).

The gamification position within kinanthropology (or Sports Sciences) is also studied in social studies in sports and their possible relation to gamification. We argue that sociological and psychological investigations could be supported by studies of the philosophical background of gamification applied in the field of sport. Some authors speak about the concept of "meaningful gamification" (Deterding, 2011). This meaningfulness is often and primarily explained from psychological positions exploring theories of motivation (Nicholson, 2012).

In the philosophical discourse, we could examine gamification from different positions. There are many ways as to how to approach this phenomenon. We would like to provide some possible directions in a brief outline and to explain some selected possibilities within this article.

\section{SOME POSSIBILITIES FOR FUTURE PHILOSOPHICAL INVESTIGATIONS OF GAMIFICATION}

After 2010, the general technological developments in gamification became linked very closely to the IT-sphere. This trend is evident, and there are not many possibilities for regulating it. The philosophical discourse contains at least some potential to allow us to try to identify some problems via some selected paradigms. They can be interesting for those searching for sophisticated methods to approach this problem, which lends itself to a dangerously mechanistic understanding. 
One of them is an ethical discourse that provides some instruments for preventing the most visible threats that present an evident public menace. In the context of the expansion of modern technologies, it is those which are related to producing weapons, genetic engineering and human cloning, deepfakes, disinformation activities, and similar phenomena that could be considered highly ethically problematic. However, some ethical rules can also be developed to take care of these problems or regulate them. Mainly, such rules are applied in the form of laws, moral norms, ethical board decisions, etc. This kind of prevention usually takes the shape of bans and prohibitions. This normative aspect of ethics is necessary, and it works in a regulative way, but it is suitable just for some cases.

Normative ethics is much more functional and efficient if applied practically than in the form of abstract philosophical thinking, which presents a more diverse space for interpretation and application than exact practical rules. In practice, we often face a functional problem that contains many contradictions. Decisions of some ethical boards can be effective and applicable to certain, specific, settings. Still, they are often instrumentalized and subordinated to various concrete orders (such as systems of law, political situations, or even business interests). The broader ethical principles that can be applied outside of these orders are not concrete and generally comprehensible enough to influence the determining mechanisms that shape social trends. That is why general social agreement is accepted when society feels the necessity facing a visible menace. This ethical approach is the most useful and efficient when there is generally a need to protect society from harm.

Concerning gamification, as it has been said, it arises as a part of technological developments, and we can consider it as an ambivalent instrument. We can find a lot of ethically troubling points here. While currently gamification's fundamental social impact is not generally understood as an urgent problem or danger that has to be solved, sharing data within different communities presents a visible outcome of using social networks (Facebook, or Instagram, especially). Via different gamification challenges leading to open competition in getting badges and other rewards, the process of sharing data could be permitted and indeed encouraged very strongly. Together with some instruments applied by artificial intelligence (like face recognition), the danger of accumulating the data obtained for some political, business, and other purposes increases (e.g., Oliveira, Ferreira \& Allisson, 2020; Nweke et al., 2019). As such, the moral threat of gamification would become a problem to be solved by different ethical boards. It also mean that some administrative steps and regulative measures caused by gamification might change the face of gamification retroactively. For this reason, in the next future, gamification should, from the outset, be accepted as ethically problematic. We propose that for the philosophy of sport, gamification's ethical aspects will not be ignored or minimised in the future.

Besides ethics, there are other viewpoints from the philosophy of sport to which gamification is open. Some of them will be mentioned here just briefly. Undoubtedly they can be significant for the philosophy of sport, but we do not want to develop them within this article. One of these aspects is related to digitalization. Gamification is, at least in some concepts, often related to the virtual sphere and cyberspace.

The philosophy of sport is a rapidly developing kinanthropological discipline and is increasingly institutionalised through a variety of academic organizations (International Association for the Philosophy of Sport, British Philosophy of Sport Association, European Association for the Philosophy of Sport, etc.). Sport, Ethics and Philosophy is a respected journal that has been published since 2007. In 2016 a special issue entitled Sport and Play in a Digital World was published (2016, Vol. 10, Issue 1). This issue was wholly devoted to digital technologies in sport. We should repeat that gamification itself is not a part of digital games per se. It represents, rather, the removing of instruments from their original settings in order to facilitate their application 
elsewhere. However, this technology was "born" in the "digital world," which is why it is interesting to follow the studies devoted to the digital sphere in the context of the philosophy of sport. The exact term "gamification" was not explicitly mentioned in any of the articles included in the special issue. However, some of the articles were focused on the ontological problems related to the phenomenon of gamification. Steven Conway examined the virtualization of sport from the Heideggerian position in his paper An earthless world: the contemporary Enframing of sport in digital games (Conway, 2016, 83-96).

The discussion about digitalization in the sphere of sport continues, even within the above mentioned journal. The very massive and visible phenomenon of e-sports draws together studies devoted to both the sphere of digital games and to the sphere of sports. Some authors argue that e-sports are not sports at all (Parry, 2019). It is difficult to anticipate the subsequent development in the terminological and theoretical discourses. Undoubtedly, if e-sports become a part of the Olympic Games in the near future, this institutional aspect will influence future academic studies. Considering Parry's position, all this broad area of e-sports might be outside the philosopher of sport's core interest. We will return to e-sports once again, in the context of play and games.

The social manifestations of gamification in sport and the cultural sphere can represent another exciting topic for investigations that combine sociological and philosophical approaches. We can identify some parallels between both the processes of gamification and sportification.

As Heere argues: "Sportification means to view, organize, or regulate a non-sport activity in such a way that it resembles a sport and allows a fair, pleasurable, and safe environment for individuals to compete and cooperate" (Heere, 2008, 21).

In a simplified explanation, we can propose that while gamification means adding game-like elements and principles in the non-game sphere, sportification means adding sport-like elements and principles in the non-sportive sphere.

Jirásek \& Kohe emphasize some aspects of sportification such as "visualizations of one's performance" or in relations between sportification and "theatricality" (Jirásek \& Kohe, 2015, 257). They treat their reference to the Renaissance principle of theatrum mundi in the case of sportification as an ontological viewpoint.

Examining the aspects of theatricality or visualization of one's performance can also be beneficial in the case of gamification. Sharing data, records, results, photos, and other attributes on social networks can be closely connected with using gamification instruments. For some users, presentations of their activities and sharing them within an internet community can be more important than carrying out the activities themselves. Psychologists can study this approach from the point of motivation, while sociologists can study this as a kind of social manifestation. For philosophers, it can be viewed as an ontological problem.

The spectrum of views that philosophy can look at in terms of the issue of gamification is undoubtedly much broader than this article can cover. Therefore, we have decided to focus on some selected ones, and to use them to show the potentiality that the phenomenon of gamification conceals.

\section{GAMIFICATION AND PLAYING A GAME - A PARADOX OR A POSSIBILITY?}

Discussions about three phenomena - play, game, and sport - have been published, over a significant period of time, in the field of the philosophy of sport. These discussions have initiated new ideas. They represent a philosophically beneficial activity, but they still have not arrived at a consensual concept. Merely the responses and reactions on Bernard Suits (Utopia and his other works) present a very long line of critical comments about the phenomenon of "play" (within 
the Journal for the Philosophy of Sport, or recently within the special issue of Sport, Ethics and Philosophy devoted to Bernard Suits' legacy - Volume 13, issue 3-4).

Generally, play is understood as an unstructured activity that is creative and engaging. A game is an activity with a set of rules, and possibly equipment, and other specific attributes. Sports can be presented as a structured form of physical activity. Terminological and structural discussions about these phenomena are still frequent. Recently, some concrete and determining attributes of sport were described in the article as mentioned above by Jim Parry (2019). Parry defines "sport" (based on the concept of an Olympic Sport) as an "institutionalised, rule-governed contest of human physical skill" (Parry, 2019, 3). That is why he argues that e-sports are games, but they are not sports, for e-sports are not a test of physical skill.

Andrew Edgar, in his editorial (to a special issue devoted to e-sports), reminds us that this issue is still developing and it "... is posing exciting new challenges to which philosophers are responding with creativity and insight” (Edgar, 2019, 2). Although e-sports, as we tried to explain, are not related to gamification directly, for more complex considerations about gamification within the philosophy of sport, the question as to how much (or even whether) e-sports will continue to be studied by philosophers of sport plays an important role. We can expect increased interest in this field because of at least two reasons: digital technologies spread rapidly, and their application is interdisciplinary.

The general concepts of the "triad" of play-game-sport are fundamental for considerations of gamification within kinanthropology. However, what is very closely related to our point is understanding the phrase "playing a game". Here we are reminded of the well-known Suits' definition of playing games: "To play a game is to engage in activity directed toward bringing about a specific state of affairs, using only means permitted by specific rules, where the means permitted by the rules are more limited in scope than they would be in the absence of the rules, and where the sole reason for accepting such limitation is to make possible such activity" (Suits, 1967, 148).

Scott Kretchmar has recently provided a redefinition which begins with this description: "To play a game is to attempt, through effort, chance, or both, to solve a natural or constructed problem; where relationships between its means (lusory means) and ends (lusory goals) provide valid challenges..." (Kretchmar, 2019, 286). Within a shorter version, Kretchmar says: “To play a game is to attempt to solve a gratuitous problem" (ibidem).

In his response to Kretchmar, Alex Wolf-Root argues (in the article called Too Much Playing Games) that this definition is too broad. In his explanation, based on creating a free verse poem, he argues that creative activities like making poetry could be understood as playing a game according to Kretchmar's definition. Wolf-Root says: "We might be left with two distinct definitions, playing a game on Kretchmar's view and 'playing a game', say using the Suitsian view, that each capture real and important aspects of gameplay” (Wolf-Root, 2020, 268). For this reason, Wolf-Root proposes rejecting Kretchmar's definition.

We do not intend to decide who is right and do not want to follow this discussion in detail. However, we should explain why these ideas can be interesting in the context of gamification.

We can come back to the definition of gamification, which speaks about adding game-like elements to the non-game settings. And, as it also was said, gamification does not mean playing games. It presents using methods created for playing games for non-game purposes.

In this context, the spirit of game is lost because of the process of gamification, and just some instruments remain. However, there is another question. What about "the spirit of playing"? Is it also necessarily lost? Coming back to Kretchmar's description of playing the game as "attempting to solve a gratuitous problem," we can imagine the situation in which one game (the original one with the exact rules) finishes. Still, a new one (played differently) could begin. 
This idea may be questioned by the definition of gamification itself (gamification is not a game).

On the other hand, this does not mean that any application of gamification elements must necessarily be deprived of playful attributes.

To illustrate these ideas, we would like to consider one concrete application of gamification - support for increased physical activity. In the next part of the article, we would like to focus on some endurance physical activities (like leisure running, cycling, or swimming), containing (in a model of non-elite movement activity for fun) some degree of spontaneity, liberty, joy, and playfulness. This is to raise the question as to what gamification can bring to this sphere.

\section{GAMIFICATION - FOCUS ON MONITORING AND CHALLENGES IN THE FIELD OF ENDURANCE ACTIVITIES}

To introduce the problem within endurance leisure sports, we must recall that some gamification instruments - based on specific game rules (badges, points, ratings) - are often used for scheduling physical activities. This scheduling is different from the previous methods of planning because it introduces some rigorous instruments that replace our responsibility for our sports schedules in the form of indoctrinated instructions. For this reason, gamification could, in some cases, result in a lower degree of playfulness.

The monitoring of physical activity represents a typical topic for studies devoted to gamification, generally. Some authors (e. g. Harris, 2018; Dadaczynski, Schiemann, \& Backhaus, 2017; Walsh \& Golbeck, 2014) pay attention to gamification aspects related to monitoring physical activity measured with some standard methods, like IPAQ (the International Physical Activity Questionnaire).

A broader expansion of investigations, based on monitoring physical activity through electronic devices, is to be expected. We can see that the sharing of the results on social networks is widespread. Developing relevant scientific studies is still limited because a great range of fitness trackers, smartwatches, or other electronic devices is produced for the practical purposes of leisure athletes. They prefer low costs, and highly exact results are not necessary for their everyday usage. That is why the most-used devices are not precise enough for scientific measures yet. However, technological developments are rapid in this sphere, and more exact devices should be produced in larger quantities in the near future.

With the massive expansion of devices monitoring our physical activity, many new possibilities for better motivation are emerging. We can apply some new interactive applications instead of our old (paper) training planners and turn them into effective instruments. Establishing shortterm and long-term goals and searching for some challenges would constitute a substantial part of planning a while ago. What is the difference, and where should we place the division between the old and new methods?

The exact boundary cannot be delimited easily, but in general, it consists of giving up our responsibility for detailed planning. In the beginning, accepting some items does not seem to be a problem. It looks like we have the opportunity to adjust everything any time we want. However, it is easy and comfortable to be led by automatically established and, what is crucial, continuously adjusted goals. Thus, our effort can be focused on keeping to the instructions without any disturbing influences. We need not think, and we do not have the opportunity to hesitate.

Within the enlarged definition of gamification, not just game-like elements are being applied to non-game domains. Still, even game-like principles and systems (like rewards, quantifying player or user-like behaviour) also penetrate the spheres that are not game-like but sport-like 
- fitness, endurance sports, etc. Here the parallel to the phenomenon of sportification can be recalled again.

A typical example of the previously committed behaviour of athletes can be presented by establishing the goal of a certain number of daily steps. Even an elementary device can automatically create a daily step count goal based on our previous activity levels. As we move during the day, the device shows our progress toward our daily goal. Undoubtedly, we are allowed to set a personalized step count goal instead of merely using the auto goal feature.

It presents a straightforward kind of a "game" - to accept the rules and "play" accordingly. Of course, the auto goal feature does not present a real danger for our authenticity, but this example can help us understand the point we wanted to display:

Although gamification does not mean playing games, applying gameful thinking presents an essential part of it. There much to be gained from our everyday activities for gameful people, or even for playful and ludic people. This ability is well articulated through the concept of "homo ludens", as described by Johan Huizinga (2016). We can see some good reasons why gamification has become an attractive and fashionable aspect of pure human playfulness. Many people who collect badges, postcards, stamps, and similar items do it because they are playful and find their activities interesting.

On the other hand, accepting rules also sometimes means adopting some mechanical structures which cannot be changed, examined, or questioned. As far as motivation and related ideas are concerned, we get closer to the "lusory goals" than "lusory means" if we use Kretchmar's distinction. From the ethical discourse, we are closer to the consequentialist position than the deontic one. If some instruments (like badges and points) are accepted just as indoctrinated goals, the instrumental approach to the world could be strengthened.

This issue can be seen via different philosophical concepts related to the question of authenticity. Concretely, we can mention instrumentality in the early Heidegger's works (Heidegger, 1997) or technologization in the late Heidegger's texts (1977). In the next section, we would like to recall Jan Patočka and his concept of three movements of human existence.

The last note of this section is connected with virtual settings and particularly in the context of gamification. Virtuality is often understood as the opposite of reality (or as an escape from reality). Thus it could be taken as something inauthentic (in the understanding of virtuality as a fiction/fictive, or even false human being). Escaping from reality into the virtual sphere presents a specific issue through the phenomenon of gamification. There are many philosophical aspects hidden in it.

One of them is included in the principle of the game. The notion of game itself contains some suggestion of escaping from natural settings into the world of fantasy and imagination. Obeying rules, sharing roles, and accepting a fictive background are all part of the game. In general, we often take this fact as something positive. We meet "the playfulness of a game" here again, remembering Kretchmar's words about our "attempts to solve a gratuitous problem". In this context, our ability to play is appreciable, and we profit from being in the "homo ludens" mode.

And, there lies the rub. If game-like elements were created to support our ability to play and if escape from reality presents a possibility, how are we to develop our playfulness; how is it possible that, in some cases, both the processes fail? As a result, we are drowned in the virtual world. Instead of a creative approach to physical activity, we fall into an automated mode in which everything is pre-arranged.

Can we identify a moment when we start "losing this game"? This question cannot be answered, generally. Athletes' approaches can be very individual. Undoubtedly, many athletes take it like this. They mechanically use simple instruments and do not need to think about it. It is clear that not all of them will appreciate a philosophical approach to this problem, but we believe 
that for many of them, it can be beneficial. And, for this reason, it can be quite a good task for the philosophy of sport.

There are many opportunities for approaching this problem. Searching for some possible philosophical interpretation of this issue that can be understood by athletes, we can propose the hermeneutical approach. According to Hans-Georg Gadamer, hermeneutics aims not at explaining but at reaching an understanding (Warnke, 1987).

This approach can help to bridge a barrier between the practical world of sport and the philosophical perspective. Hermeneutics was involved in developing possible interpretations of the Bible, but later it was expanded and related to other significant texts. Generally, it is perceived as the art of interpretation. The hermeneutical circle contains not just the author and the text, but it also includes a reader. It presents a circular movement of understanding with repeating turns from the whole to the parts. This process can be effective in leading to a deeper understanding of the issue which the participants influence. Jirásek, Hurych, and Oborný (2019) describe some benefits of the hermeneutical method for athletes who do not read philosophical books but search for a deeper personal understanding. Thus they may come to find the activities they carry out more meaningful.

Hermeneutic interpretations can include the feelings and opinions of the participants. That is why, in the case of gamification, we must get closer to them and understand better what it is about gamification that they concretely consider to be a problem.

\section{THE ONTOLOGICAL APPROACH BASED ON THE IDEAS OF JAN PATOČKA}

The ontological discourse offers many different perspectives for considering gamification as a phenomenon. The ontological approach focuses on the meaningfulness and significance of the examined issue, which also provides some exciting viewpoints via the phenomena of authenticity or instrumentality. Here we can propose one selected point based on primarily a sociological distinction provided by Woodcock and Johnson (2018), which divides gamification into two different concepts. We offer to combine the original one with the philosophical approach to make an effect of synergy. It is not a profound study. We just want to display an example of one possible way as to how future studies could be developed.

Some sociologists perceive gamification as profoundly problematic because it represents "the capture of 'play' in the pursuit of neoliberal rationalization and the managerial optimization of working life and labour," as Woodcock and Johnson $(2018,542)$ argue. These authors remind us that "applying games and play to our ordinary lives can present a form of resistance against the regularity and standardization of everyday behaviour" (ibidem). In their article, the authors also distinguish between two types of gamification: gamification-from-above (involving the optimization and rationalizing of work practices by management); and gamification-from-below (a form of active resistance against control at work often represented by Autonomism and Situationism).

We can add that the former type of gamification is very close to business strategy, as Hamari et al. (2015) present. In the model presented by Woodcock and Johnson, gamification-from-above means an instrument that works through indoctrination. The role of managers here is to schedule tasks via systems of motivation different to the usual ones, and the recipients' position is relatively passive. They can just influence the rate of their participation in this "game", but usually, there are not so many possibilities for their active involvement. However, it is much more complicated in the real world than in the field of model construction. 
Here we can mention Jan Patočka and his book called Heretical Essays in the Philosophy of History. Patockka speaks about three kinds of movement in human life here. The movement of acceptance represents a "rooting" into the world. "To this movement there belongs, not as a part but as its integrating core, a certain self-under-standing, understanding of our fundamental possibilities, which first makes it possible to sense, to encounter things as being in the world and at the same time to intervene in that world by movement" (Patočka, 1998, 157).

Some kind of acceptance could be observable in the concept of gamification-from-above. The main reason we mention Patočka's model of human existence here is that his concept can help us to understand the diversity of real situations that no model can fully cover. Patočka himself speaks about "self-under-standing", or "understanding of our fundamental possibilities" within the movement of acceptance. It means that he doesn't understand this movement as something just passive and simple. It can present an intense and sophisticated process that can contain and demand a robust intellectual effort. On the other hand, what is significant is that this kind of movement lacks active defence and aspects of self-transcendence. In this spirit, we can conceive of gamification-from-above, which can be received mechanically and in a passive mode, but not necessarily. There can be a deep understanding of the spirit through the scheduled game and the inner identification of some participants with the rules.

The second type proposed by Woodcock and Johnson, gamification-from-below, can be (in a simplified form) defined as an active resistance against control at work. Here we can recall Patočka's movement of defence. It is not strictly divided from the movement of acceptance. We have to accept the world, and we should learn a lot and understand a lot before we start defending our positions. The phenomenon of understanding is primarily anchored in the movement of acceptance. The movement of defence can be developed in different ways. (Intuitively, it is present even in the behaviour of a baby who doesn't like a person touching her.) However, Patočka sees all three kinds of movement in a complex way. Our explanation of the primary relations within the movement of defence (which can indeed be disputed) is that the higher legitimacy of it is connected with acceptance and a deeper understanding of the outer world and our being. Of course, anybody can defend himself in different ways, but that is not the determining point of Patočka's concept.

In our opinion, we can understand gamification-from-below in the context of the legitimacy of this resistance. Given this approach, we propose to analyze Patočka's concept of the movement of defence more in detail within possible future studies. It could help us understand the context of something that we can label as a "playful resistance" and which is hidden in gamificationfrom-below.

And, there is one more exciting point concerning the movement of defence. Patočka also calls it "movement of self-extension," or "self-projection into things" (ibidem). The phenomenon of self-extension can have many forms (self-education, building a career, a kind of conquest, etc.). It can also be perceived as enlarging our radius of action or expanding our sphere of influence. The playful resistance included in gamification-from-below can contain (besides a very personal aspect) a form of group-organized reaction to some indoctrinated settings, or even, in some cases, expanding this effort. This form of self-extension can lead back to gamification-from-above, in a paradoxical output where the old one is replaced by the new one on a different level.

Some electronic devices can present a phenomenon which could be metaphorically expressed as our "extended hands". It can help us to expand our sphere of influence (we have "longer hands" to reach), but there is a risk of dependence on these instruments. Thus "self-projection into things" can lead to a kind of dependence on instruments as a symptom of the inauthentic way of being. Here we can remember Heidegger's ideas about instrumentalization and technologization again. 
The most significant movement for Patočka was the last one: the movement of the truth. Patočka also speaks about the movement of existence in a narrow sense $(1998,148)$. The movement of truth brings a possibility for a deeper understanding of our being. This movement includes a turn towards authenticity. The authentic position is related to accepting more responsibility for our behaviour. As Martínková $(2006,65)$ mentions: "Responsibility can no longer be placed on one's teachers, coaches and doctors, but on oneself."

The movement of truth represents a complex process. One of its attributes is also based on overcoming the "self-position". Kohák $(1989,33)$ emphasizes this attribute and speaks about the "self-transcendence movement". Thus one of the aspects of this movement can be seen in escaping from our egoistic interests and searching for some general profit. The backgrounds of the movement of truth could provide some space for considerations about gamification-form-above and gamification-form-below concerning responsibility for our behaviour in the context of the examining modes of authenticity.

Patočka's concept of three human movements presents a very sophisticated complex of ideas. We believe that in this complex, we can also find the point of contact with the hermeneutic method. It consists of a focus on a deeper understanding of the outer world.

We do not argue that our position is indisputable or that it is the only one that can be applied to the phenomenon of gamification. Here we want to provide some possible directions for future, more detailed, studies.

\section{CONCLUSIONS}

This article presents just a modest outline, in the form of an introduction to the problem of gamification from the philosophical perspective. Gamification is a phenomenon that has been frequently examined in the scientific literature over the last decade. Gamification in sport is monitored and studied from different positions (sociology, pedagogy, or management). On the other hand, not many works investigate gamification through philosophical discourse. For the philosophy of sport, some digital aspects of sport and problems of virtualization have already become exciting topics to study, but these studies were not focused on gamification directly.

This paper's point is to propose some opportunities through which philosophical approaches to gamification can be developed. As a process that influences the monitoring and scheduling of endurance sport activities, gamification can be exciting for practical reasons in both ontological and ethical discourses. The triad play-game-sport provides some space for philosophical investigations with respect to the relation between gamification and sportification. The sociological study by Woodcock and Johnson examined via Patočka's concept of three movements of human existence was included in the article mainly as an example to illustrate the great diversity of possible philosophical approaches.

We believe that gamification in sports will be considered more and more in future scientific investigations because many people use different electronic gadgets and applications based on diverse elements of gamification. The philosophy of sport shouldn't ignore this rapidly growing trend.

\section{References}

Allam, A., \& Kostova, Z., Nakamoto, K. \& Schulz, P. J. (2015). The effect of social support features and gamification on a web-based intervention for rheumatoid arthritis patients: Randomized controlled trial. Journal of Medical Internet Research, 17(1), e14. 
Broom, D. R., Flint, S. W. (2018). Gotta catch 'em all: Impact of Pokemon go on physical activity, sitting time, and perceptions of physical activity and health at baseline and three-month follow-up. Games for Health Journal, 7(6).

Çeker, E. \& Özdaml, F. (2017). What "Gamification" is and what it's not. European Journal of Contemporary Education, 6(2): 221-228.

Codish, D. \& Ravid, G. (2014). Personality based gamification - educational gamification for extroverts and introverts. Paper presented at Proceedings of the 9th Chais Conference for the Study of Innovation and Learning Technologies: Learning in the Technological Era, Israel.

Conway, S. (2016). An earthless world: the contemporary Enframing of sport in digital games, Sport, Ethics and Philosophy, 10(1), 83-96.

Dadaczynski, K., Schiemann, S. \& Backhaus, O. (2017). Promoting physical activity in worksite settings: Results of a German pilot study of the online intervention Healingo fit. BMC Public Health, 17(1), 6.

Deterding, S. (2011). Meaningful Play: Getting "Gamification" Right. Google Tech Talk. Available at: http://www. slideshare.net/dings/meaningful-play-getting-gamification-right, Accessed 29 March 2021.

Edgar, A. (2019). Esport. Sport, Ethics and Philosophy, 13(1), 1-2.

Gabele, M., Thoms, A., Alpers, J., Hußlein, S, \& Hansen, C. (2019). Effects of interactive storytelling and quests in cognitive rehabilitation for adults. In J. Koivisto \& J. Hamari. Proceedings of the 3rd International GamiFIN conference [pp. 118-129]. Levi, Finland, April 8-10, 2019.

Gremaud, A. L., Carr, L. J., Simmering, J. E., Evans, N. J., Cremer, J. F., Segre, A. M., et al. (2018). Gamifying accelerometer use increases physical activity levels of sedentary office workers. Journal of the American Heart Association, 7(13), 10 (2018).

Hamari, J., Sjöklint, M. \& Ukkonen, A. (2015). The Sharing Economy: Why People Participate in Collaborative Consumption. Journal of the Association for Information Science and Technology, 67(9), 2047-2059.

Harris, M. A (2018). Beat the street: A pilot evaluation of a community-wide gamification-based physical activity intervention. Games for Health Journal 7(3), 208-212.

Heere, B. (2018). Embracing the sportification of society: Defining e-sports through a polymorphic view on sport. Sport Management Review, 21(1), 21-24.

Heidegger, M. (1996). Being and Time. Albany (NY): State University of New York Press.

Heidegger, M. (1977). The question concerning technology and other essays. Edited by W. Lovitt. New York, NY: Garland Publishing.

Huizinga, J. (2016). Homo Ludens: A Study of the Play-Element in Culture. London: Routledge and Kegan Paul, Ltd.

Jirásek, I. \& Kohe, G. (2015). Readjusting Our Sporting Sites/Sight: Sportification and the Theatricality of Social Life. Sport, Ethics and Philosophy, 9(3), 257-270.

Jirásek, I., Hurych, E. \& Oborný, J. (2019). Hermenuticals of Human Movement and Sport: Holism and Harmony. Physical Culture and Sport Studies and Research 79(1), 5-15.

Kim, B., Park, H., \& Baek, Y. (2009). Not just fun, but serious strategies: Using Meta cognitive strategies in game-based learning. Computers \& Education, 52(4), 800-810.

Kohák, E. (1989). Jan Patočka: Philosophy and selected writings. Chicago \& London: The University of Chicago Press.

Koivisto, J., \& Hamari, J. (2019a). Gamification of physical activity: A systematic literature review of comparison studies. In J. Koivisto \& J. Hamari. Proceedings of the 3rd International GamiFIN conference. [pp 106-117]. Levi, Finland, April 8-10, 2019.

Koivisto, J., \& Hamari, J. (2019b). The rise of motivational information systems: A review of gamification research. International Journal of Information Management 45, 191-210 (2019).

Kretchmar, S. (2019). A revised definition of games: An analysis of grasshopper errors, omissions, and ambiguities. Sport, Ethics and Philosophy, 13(3-4), 277-292.

Martínez-González, M. Á., Martinez, J. A., Hu, F. B., Gibney, M. J. \& Kearney, J. (1999). Physical inactivity, sedentary lifestyle and obesity in the European Union. International Journal of Obesity, 23(11), 1192-1201.

Martínková, I. (2006). Jan Patočka's Three Movements of Human Life with Respect to Physical Education and Sport Practice. Acta Universitatis Palackianae Olomucensis. Gymnica, 36(2), 59-66.

Nweke, H. F., Teh, Y. W., Mujtaba, G. \& Al-Garadi, M .A. (2019). Data fusion and multiple classifier systems for human activity detection and health monitoring: Review and open research directions. Inf. Fusion, 46, 147-170.

Oliveira, A., Ferreira, H. \& Alisson, P. (2020). Artificial Intelligence for Social Media Safety and Security. International Business Management 14(7), 236-243. 
Parry, J. (2019). E-sports are not sports. Sport, Ethics and Philosophy, 13(1), 3-18.

Patočka, J. (1998). Body, community, language, world. Chicago and La Salle (Illinois): Carus Publishing Company. Translated by Erazim Kohák.

Patočka, J. (1996). Heretical Essays in the Philosophy of History. Peru (Illinois): Open Court Publishing Company. Translated by Erazim Kohák.

Peng, W., Lin, J. H., \& Crouse, J. (2011). Is playing exergames really exercising? A meta-analysis of energy expenditure in active video games. Cyberpsychology, Behavior, and Social Networking, 14(11), 681-688.

Ranchhod, A., Gurău, C., Loukis, E. \& Trivedi, R. (2014). Evaluating the educational effectiveness of simulation games: A value generation model. Information Sciences, 274, 75-90.

Sailer, M., Hence, J. U., Mayra, S. K. \& Mandl, H. (2017). How gamification motivates: An experimental study of the effects of specific game design elements on psychological need satisfaction. Computers in Human Behavior, 69, 371-380.

Suits, B. (1967). What is a game? Philosophy of Science 34(2), 148-156.

Walsh, G. \& Golbeck, J. (2014). StepCity: A preliminary investigation of a personal informatics-based social game on behavior change. In: HI'14 Extended Abstracts on Human Factors in Computing Systems [pp. 2371-2376].

Warnke, G. (1987). Gadamer: Hermeneutics, Tradition and Reason. Stanford: Stanford University Press.

Wolf-Root, A. (2020). Too Much Playing Games - A Response to Kretchmar. Sport, Ethics and Philosophy, 14(2), 264-268.

Woodcock, J. \& Johnson, M. R. (2018). Gamification: What it is, and how to fight it. The Sociological Revue. 66(3), 542-558. 